\title{
Mean T Wave Height
}

National Cancer Institute

\section{Source}

National Cancer Institute. Mean T Wave Height. NCI Thesaurus. Code C62149.

The average (mean) height (usually measured in $\mathrm{mm}$ ) of the maximum deflection from baseline of the T wave (representing ventricular repolarization), obtained from a set of measurements of the T wave, from a single lead or set of leads. 